This is an Accepted Manuscript of an article published by Taylor and Francis in Global Public Health on 10 April 2014. Available online:

http://www.tandfonline.com [Article DOI: 10.1080/17441692.2014.9034280]

\title{
HIV prevention: Making male circumcision the 'right' tool for the job
}

\author{
Kirsten Bell \\ Department of Anthropology, University of British Columbia, Vancouver, Canada
}

\begin{abstract}
In recent years, HIV/AIDS programming has been transformed by an ostensibly 'new' procedure: male circumcision. This article examines the rise of male circumcision as the 'right' HIV prevention tool. Treating this controversial topic as a 'matter of concern' rather than a 'matter of fact', I examine the reasons why male circumcision came to be seen as a partial solution to the problem of HIV transmission in the twenty-first century and to what effect. Grounded in a close reading of the primary literature, I suggest that the embrace of male circumcision in HIV prevention must be understood in relation to three factors: 1) the rise of evidence-based medicine as the dominant paradigm for conceptualizing medical knowledge, 2) the fraught politics of HIV/AIDS research and funding, which made the possibility of a biomedical intervention attractive, and 3) underlying assumptions about the nature of African 'culture' and 'sexuality'. I conclude by stressing the need to expand the parameters of the debate beyond the current polarized landscape, which presents us with a problematic either/or scenario regarding the efficacy of male circumcision.
\end{abstract}

Keywords: male circumcision, HIV prevention, scientific facts, social studies of science, controversy

\section{Introduction}

Over the past eight years, an ostensibly 'new' procedure has transformed HIV/AIDS prevention. Touted as a "surgical vaccine" (Rose, 2010), male circumcision has been celebrated as an unprecedented breakthrough in the fight against HIV/AIDS (UNAIDS, 2007a). According to UNAIDS:

Male circumcision is the most compelling evidence based prevention strategy since the finding that antiretroviral medicine can reduce mother-to child transmission of HIV. Governments, supported by non-governmental organizations, multilateral and bilateral development partners and others, need to make the decisive action now to make this life-saving strategy affordable and safely available to relevant populations bearing the heaviest burden of HIV infection (2007a, p. 2).

In many respects, UNAIDS' endorsement of male circumcision appears to be the consequence of evidence-based medicine in action. A series of observational studies indicating an inverse correlation between male circumcision and HIV status culminated in the development of randomized controlled trials (RCTs) to test the relationship. After three RCTs found that male circumcision reduces the incidence 
of HIV, and a Cochrane review confirmed the efficacy of the procedure, the study findings were taken up by key stakeholders and integrated into HIV/AIDS prevention programming. Consequently, male circumcision is now being offered as a part of a comprehensive HIV/AIDS package in various sub-Saharan African countries and its feasibility as an intervention is being explored well beyond it.

This is the official story of how male circumcision was integrated into HIV/AIDS prevention programming. However, in this essay I move beyond standard public health representations of the transition from evidence to practice by examining the ways that male circumcision was made into the 'right' tool for the job of reducing HIV transmission. As Casper and Clarke (1998) observe in their analysis of the emergence of the pap smear, multiple actors both inside and outside of the cancer arena were required to make this screening tool—one with fundamental ambiguities in its ability to detect cervical cancer-'work' as a screening procedure. Their account shows that tools do not become such because they are indisputably 'right'; rather, "rightness' and 'wrongness' are socially constructed, relative, partial, situated and contingent" (p. 257). Thus, biomedical technologies of prevention are the result of negotiations, choices and contingencies embodying socially and culturally constituted values and practices (Oudshoorn, 2003, p. 10).

I want to emphasize that in examining the contingent nature of scientific and biomedical practices, I am not attempting to reinstate a constructivist/essentialist divide that takes flight from the materiality of the body. Nor am I trying to set myself up as the debunker who alone has privileged access to the 'truth' of male circumcision. As Latour (2004) has shown, this particular form of critical spirit has led to a kind of empty analysis that allows us to be constructivists about everything we don't believe in and positivists about everything we do, which places us in the felicitous position of always being right. As I aim to show, it is on precisely these terms that the debate about male circumcision has unfolded to date, which has led to a situation of implacable oppositions between those in favor of the procedure and those against it, with each party claiming to represent the side of science. In this paper I attempt to sidestep the current stalemate by treating the link between male circumcision and HIV transmission as a 'matter of concern' rather than a 'matter of fact' (Latour, 2004). A matter of concern is "what happens to a matter of fact when you add to it its whole scenography, much like you would do by shifting your attention from the stage to the whole machinery of a theater" (Latour, 2008, p. 39). It is to recognize that 'facts', while not reducible to mere social constructions, are nevertheless inseparable from particular thought collectives and styles, and must be studied within their social and chronological context (Fleck, 1979).

First, some caveats. I write this paper not as an Africanist or someone who specializes in HIV/AIDS; my position is that of an agnostic observer, albeit one with a longstanding interest in discourses on male and female genital cutting (Bell, 2005) and an entirely separate interest in the rise of evidence-based medicine and its 'creep' into public health (Bell, 2012). Over the past six years, these interests have begun to collide in the context of male circumcision and HIV prevention. There is little doubt that the readiness to endorse male circumcision in the context of HIV prevention is affected to some extent by the culturally normalized status of male genital surgery as "trivial and inconsequential... just a little snip" (Aggleton, 2007, 
p. 15). For example, Carpenter (2010) has shown that the remedicalization of male circumcision in the context of HIV prevention has been more enthusiastically embraced in the US than the UK, where both circumcision and HIV rates are substantially lower. Carpenter's research suggests that the prevalence of HIV/AIDS is an important factor in the willingness to pursue male circumcision as a viable response, but so too is the degree to which it is already practiced. However, while it is clear that this is an important antecedent for the uptake of the procedure, this tells us little about why it was taken up. It is this question that forms the central problematic of this essay.

\section{An overview of the rise of male circumcision as a HIV prevention technology}

The first person to posit an association between male circumcision and HIV transmission was Andrew J. Fink, an advocate of mass circumcision (see Fink, 1988). In 1986 he published a letter to the editor in the New England Journal of Medicine speculating on a connection between the two. ${ }^{1}$ In Fink's words:

It has been known for many years and has recently been documented again in studies in venereal disease clinics that both genital herpes and syphilis are more common in uncircumcised men... I suspect that men in the US, who, as compared with those in Africa and elsewhere, have had less acquisition of AIDS, have benefited from the high rate of newborn circumcision in the US, which was 80 to 90 percent until recently, but is now rapidly declining ( $p$. 1167).

The extent to which Fink's letter provided an impetus for the subsequent series of publications reporting inverse relationships between HIV infection and male circumcision in sub-Saharan Africa is unclear, as some-but certainly not all-make reference to his article. It's also worth noting that the initial findings on the association were generally reported in the context of studies focusing on the relationship between HIV and genital ulcers, rather than male circumcision specifically (e.g., Greenblatt et al., 1988; Cameron et al., 1989; Hira et al., 1990). However, during this period studies also began to map patterns of HIV transmission and male circumcision in sub-Saharan Africa and documented an inverse correlation between the two (e.g., Bongaarts et al., 1989; Moses et al., 1990; Caldwell \& Caldwell, 1994). With some notable exceptions (e.g., Barongo et al., 1992; Pison et al., 1993), studies throughout the 1990s continued to find inverse correlations between HIV infection rates and male circumcision (e.g., Gilks et al., 1992; Bwayo et al., 1994; Mbugua et al., 1995). However, they often advocated caution in interpreting this association, highlighting evidence of important confounders such as marital status, age, history of commercial sex encounters, and so on. Studies also found that the protective effect of male circumcision differed across populations and age groups (e.g., Urassa et al., 1997; Quigley et al., 1997; Kelly et al., 1999).

Although the tone of the early observational research was generally qualified, the possibility of implementing male circumcision in the context of HIV prevention was raised in 1994 (de Vincenzi \& Mertens, 1994). By 1999 resounding calls for the introduction of male circumcision in the context of HIV prevention were being made. Highlighting the findings of the observational studies, Halperin and Bailey (1999, p. 1813) argued that: "It is time for the international health community to add male- 
circumcision services to the current limited armamentarium of AIDS prevention measures in countries with a high prevalence of heterosexually transmitted HIV and STDs". A meta-analysis published the following year (Weiss et al., 2000) also stressed the potential public health benefit of introducing male circumcision services, concluding that male circumcision halved the risk of HIV infection among men in sub-Saharan Africa. However, a subsequent Cochrane review of observational studies (Siegfried et al., 2005) was more conservative in its conclusions. Raising concerns about the heterogeneity of the existing research, the authors elected not to conduct a meta-analysis and argued that:

Although the positive results of these observational studies suggest that circumcision is an intervention worth evaluating in randomised controlled trials, the current quality of evidence is insufficient to consider implementation of circumcision as a public-health intervention (p. 172). Clearly, the Cochrane reviewers were not prepared to take a firm position on the evidence without the results of RCTs (which were underway at the time of the review).

Later that year, Auvert et al. published the findings on the first RCT in PLoS Medicine. The study, which involved 3,274 uncircumcised men between 18-24 years of age from Orange Farm and surrounding areas just outside of Johannesburg, South Africa, suggested that male circumcision conferred a $60 \%$ protection against HIV. The trial was stopped at the interim analysis because the findings were deemed so compelling that the requirement of clinical equipoise was no longer met, and they were ethically bound to offer the treatment to men in the control arm of the study. Consequently, almost a third of the sample did not complete all of the followup visits at 24 months, with the mean follow-up at 18.1 months when the data were analyzed.

In 2007, the findings of a further two RCTs were published. Gray et al.'s (2007) RCT took place near the Lake Victoria region in Rakai, Uganda, with 4,996 men aged 1549 years of age. Like the earlier Orange Farm RCT, the study was stopped at the second interim analysis due to "significant efficacy" (as treated efficacy was 55\%); thus, of the 4,996 men enrolled, only $39 \%$ completed the trial to the 24 -month followup. Also in the Lake Victoria region, Bailey et al.'s (2007) RCT took place in Kisumu, Kenya with 2,784 men, predominantly from the Luo tribe, who traditionally do not circumcise. The trial was also stopped early after the third interim analysis, although $86 \%$ of men completed the 24 -month follow up. The researchers found that male circumcision reduced the risk of HIV transmission by $53 \%$, with the protective effect rising to $60 \%$ after controlling for non-adherence to treatment and excluding four men found to be HIV+ at enrolment. A fourth RCT was cancelled due to slow enrollment (UNAIDS, 2008).

The results of both trials were published in the same issue of the Lancet, along with two accompanying editorials, both of which argued that the RCTs provided firm evidence that male circumcision halved the risk of acquiring HIV, constituting a "solid evidence base" to inform health policy (Lancet, 2007; Newell \& Bärnighausen, 2007). Two weeks following the Lancet publication and editorials, WHO/UNAIDS officially endorsed male circumcision as a HIV prevention tool, with UNAIDS (2007b, p. 4) stating that "The efficacy of male circumcision in reducing female to 
male transmission of HIV has been proven beyond reasonable doubt. This is an important landmark in the history of HIV prevention". However, amidst the clamors for intervention, a few voices urged the need to proceed with care. For example, Dowsett and Crouch (2007, p. 42) asked:

Is there enough evidence to proceed? We believe we need to know much more about male circumcision for HIV prevention before adopting it as a population health measure. The WHO/UNAIDS Statement is cautious in noting the existence of caveats and gaps, but it argues that it is time to go ahead. We would argue that there is still much work to do before national authorities and the global HIV/AIDS community can feel confident about proceeding.

The first meta-analysis of the three RCTs (Mills et al. 2008) was also cautious in tone. While the authors concluded that: "Male circumcision is an effective strategy for reducing new male HIV infections" (p. 332), they emphasized the importance of "consistently safe sexual practices to maintain the protective benefit" and the lack of available evidence regarding the impact of circumcision on sexual risk behaviors. An accompanying editorial (Lazarus, Giordano \& Matic, 2008) outlined a number of additional caveats, pointing to the difficulty of extrapolating the trial results to a 'real world' environment and the implausibly large treatment effects of stopping trials early. The editors also highlighted the fact that trial participants were extensively counseled about the need for sexual abstinence and condom use and given free access to condoms, which would have significantly affected the intervention's efficacy.

Much of this uncertainty disappeared in the Cochrane review published the following year on the three RCTs (Siegfried et al., 2009). Although the Cochrane reviewers acknowledged that the premature stoppage of the trials introduced a potentially high risk of bias, they argued that the consistency of the results across the trials "strengthens the evidence in favour of circumcision" (p. 18). They concluded that medical male circumcision reduces the acquisition of HIV by heterosexual men by 38\%-66\% over 24 months, and that "inclusion of male circumcision into current HIV prevention measures guidelines is warranted", although research to assess its feasibility, desirability and cost effectiveness in local contexts was necessary (p. 1).

Following the publication of the Cochrane review, several agencies channeled funding into large scale, rapid implementation, countrywide projects. For example, USAID and the U.S. President's Emergency Plan for AIDS Relief (PEPFAR) currently promote voluntary medical male circumcision as a part of a larger coordinated HIV prevention plan including sexual partner reduction, correct and consistent condom use and other behavioral changes (USAID, 2011). Their recent initiatives include the Accelerated Saturation Initiative in Swazliand, which aimed to circumcise between 125,000 and 175,000 Swazi males from ages 15 to 49 in a 12 month period and Tanzania's first high-volume male circumcision campaign, which circumcised 10,378 males in a 6-week campaign in 2010 and they are also involved in male circumcision initiatives in Botswana and Zambia. By 2013, they had directly supported more than 4.2 million male circumcision procedures worldwide (PEPFAR, 2013). The Bill and Melinda Gates Foundation has also channeled at 
least $\$ 50$ million into male circumcision initiatives in Zambia and Swaziland aiming to circumcise 642,000 adolescent boys and men over a five-year period (Ncayiyana, 2011).

Although many of these programs have been top-down initiatives, a number of African men themselves are seeking out the operation in large numbers. As previously noted, the fourth planned RCT was cancelled due to low enrollment, suggesting that local populations had decided for themselves that male circumcision was efficacious and no more trials were required. Westercamp and Bailey's (2007) literature review on the acceptability of male circumcision for HIV/AIDS in subSaharan Africa emphasizes the pervasiveness of this view. Conducted before the results of the final two RCTs were published, the review states that "If MC is proven in the remaining two clinical trials to reduce incidence of HIV and some STIs, this information will be consistent with the already existing beliefs of most sub-Saharan Africans" (pp. 352-353). Various African-based community organizations are also calling for a scaling up of voluntary male circumcision programs (e.g. Avac et al., 2012), although some African medical professionals have spoken out against the inclusion of the procedure in HIV prevention initiatives (e.g., Ncayiyana, 2011).

\section{Debating the evidence}

Clearly, the view that questions about the efficacy of male circumcision in HIV prevention have been definitely resolved has a wide degree of circulation in the academic and policy literature. As de Camargo Jr et al. (2013, p. 775) note, Currently, articles with the greatest visibility (published in the most important journals) seem to deal exclusively with theoretical and empirical 'adjustments' to the already hegemonic paradigm defending the causal relation between MC and protection against contamination by HIV.

Although various academics have expressed concerns about the wisdom of introducing male circumcision as a HIV prevention tool (e.g., Aggleton, 2007; Berer, 2007; Dowsett \& Crouch, 2007; Fox \& Thomson, 2010; Green et al., 2008, 2010), the most vocal and sustained criticisms have come from anti-circumcision advocates (e.g., Van Howe, Svoboda \& Hodges, 2005; Van Howe \& Storms, 2011; Boyle \& Hill, 2011). In many respects, it was inevitable that the relationship between male circumcision and HIV transmission would become embroiled in this much larger and longstanding debate about medical and religious male circumcision. However, this context has meant that "debates concerning the role of male circumcision in the fight against HIV/AIDS are often polarized between those who flatly reject and those who strongly embrace this use of male circumcision" (Rennie, 2007, pp. 731-732).

Although those both for and against the use of male circumcision as a HIV prevention tool tend to express themselves in absolute terms, these are not monolithic groups. As Klawiter (2008) has illustrated, social movements are often comprised of distinct but overlapping 'cultures of action' which privilege different body politics, identities, strategies and emotions. Thus, the movement to introduce male circumcision into HIV prevention programming has led to alliances between researchers, clinicians, pro-circumcision advocates, religious leaders and moral entrepreneurs (Aggleton, 2007). Likewise, the anti-circumcision movement has generated coalitions between the men's movement, Christian groups and 
organizations concerned with genital integrity, a mélange that has resulted in a distinctly conspiratorialist, anti-Semitic and anti-feminist tone to some segments of anti-circumcision advocacy ${ }^{2}$ (see Silverman, 2006 for further discussion). The differing alliances forged in both of these contexts speak to the 'strange bedfellows' that politicized issues produce, where the positions of individuals with radically differing politics and ideologies occasionally converge (see Gard, 2011).

Despite their different thought styles, the arguments made on both sides of the male circumcision/HIV prevention debate are strikingly similar, a point de Camargo Jr et al. (2013) have made in their recent examination of the male circumcision and HIV controversy. As they show, although the fault lines of the controversy are constituted along the lines of the 'natural side' versus the 'social side', similar epistemological and axiological conceptions underwrite each. Indeed, both sides simultaneously invoke what Latour (2004) has called the 'fact' and the 'fairy' positions-i.e., presenting their own arguments as neutral scientific facts and the opposition as fetishists who (depending on the position taken) either demonize or valorize the foreskin.

For example, in a critique of the three RCTs, Boyle and Hill (2011) argue that "The RCT lead authors all held pre-existing beliefs as to the 'benefits' of male circumcision and cited articles that supported their pro-male circumcision opinions" (p. 331). They conclude with their own ostensibly 'neutral' assessment of the facts of circumcision: "Male circumcision is a dangerous distraction and waste of scarce resources that should be used for known preventive measures" (p. 333). Wamai et al. (2012), in their response to Boyle and Hill's article, present their own critique in virtually identical terms, stating:

When self-identified opponents of male circumcision reject research results, misrepresent the literature, use selective citations and resort to misleading statements in order to assert their long-standing anti-male circumcision agenda, they also reject established scientific norms and rules, so making scientific discourse all but impossible (p. 119).

Their goal, as they explain it, is to "put science back at the core" of the debate on male circumcision for HIV prevention (p. 94).

As these commentaries illustrate, there is a degree of hypocrisy (and a great deal of hyperbole) on both sides of the debate. Thus, Boyle and Hill state that "When undertaking research into male circumcision, full disclosure of personal beliefs indicative of likely biases should include professional, religious, political and cultural affiliations, as well as one's own circumcision status" (p. 331-332), but fail to heed their own advice. Similarly, Wamai et al.'s admonishment that "when criticisms are spurious, and possibly made to support a particular ideology or 'cause', harm to science and society can result" (p. 95) rings a little hollow, given that the second author on the paper is a longstanding advocate of mass circumcision who runs the pro-circumcision website www.circinfo.net.

This framing presents us with two possibilities for understanding the relationship between male circumcision and HIV transmission. According to the dominant perspective, the role of male circumcision in reducing HIV transmission is an indisputable matter of fact and those who "continue to question its effectiveness 
would deny millions of men-and their female partners-a proven, permanent, and inexpensive method to reduce their lifetime risk of HIV infection" (Banerjee et al., 2011, p. e11). According to the minority perspective, the link is the result of shoddy research conducted to further a pro-circumcision agenda-one that in some accounts reaches the status of a vast global conspiracy. Neither position leaves much room for open discussion and debate. Either questions about the evidence are tantamount to heresy: "Such denialism in the face of the ongoing pandemic are unethical and immoral" Banerjee et al. (2011, p. e11) chide, or no amount of evidence would constitute 'enough'-each study becomes further proof of the subversion of science for political purposes.

Are these the only frames through which we can consider the relationship between male circumcision and HIV prevention? I would suggest the need to shift the terms of the debate. If we move away from thinking about facts as simply 'there whether you like it or not' to recognizing that they have to be liked, appreciated and taken up, then "matters of fact begin to look different, to render a different sound, they start to move in all directions, they overflow their boundaries, they include a complete set of new actors, they reveal the fragile envelopes in which they are housed" (Latour, 2008 , p. 39). From my point of view, a more productive question is why male circumcision came to be seen as a partial solution to the problem of HIV transmission in the twenty-first century and to what effect. Put another way, what forces had to gather to hold this view firmly in place (cf. Latour, 2004, p. 246)?

\section{The rise of evidence-based medicine}

As I have already alluded, to understand why male circumcision came to be seen as a viable means of preventing HIV transmission we must consider the confluence of various external forces beyond the evidence itself. After all, calls have been made to introduce male circumcision into HIV prevention programming since the mid-1990s, so what substantively changed? Obviously, the three RCTs were integral, but to fully understand their significance we must examine in more detail the rise of evidence-based medicine in the 1990s as the dominant paradigm for conceptualizing medical knowledge.

Although key features of what became the EBM movement were originally articulated in the 1970s, the term 'evidence-based medicine' was coined by a group of clinical epidemiologists in 1992. EBM was announced with considerable fanfare as a new paradigm that would move the practice of medicine beyond idiosyncratic decision making towards a careful review of the best available research evidence (Mykalovskiy \& Weir, 2004). Promoted with evangelical zeal (Traynor, 2000), as an instrument of accountability, in principle EBM is almost impossible to challenge (Bell, 2012). This self-evident value has therefore enabled the creep of 'evidencebased healthcare' (as the movement has become more broadly known) into domains outside of clinical medicine, and subsequent iterations of EBM soon expanded its gaze to other aspects of health-related activity, including multilevel and complex behavioral interventions targeting whole communities (Victora, Habicht \& Bryce, 2004; McGuire et al., 2005; Bell, 2012). EBM 'creep' has also seen the movement's central tenets applied to fields far removed from health and medicine, assuming a seamless transposition of principles and processes (Bell, 2012). 
At the heart of the EBM movement is the Cochrane Collaboration (Traynor, 2000; Cohen, Stavri \& Hersh, 2004), an organization named after Archie Cochrane, a British epidemiologist who advocated the use of RCTs as a means of informing healthcare practice. Cochrane reviews are the central activity of the Cochrane Collaboration. Using a prescribed process and methodology which treats RCTs as the 'gold standard' of research evidence, reviewers scrutinize the published literature to determine its quality and summarize the evidence of efficacy of a variety of healthcare interventions. Although critics have attacked the movement on a wide variety of fronts, from its philosophical underpinnings, methodological flaws and anti-humanist 'one size fits all' orientation, to the ways EBM principles align with the neoliberal restructuring of the welfare state (see Cohen, Stavri \& Hersh, 2004; Mykhalovskiy \& Weir, 2004; Goldenberg, 2006; Lambert, 2006), these criticisms have not made a noticeable dent on the enthusiasm for EBM principles in medicine and public health. Nor have they dislodged the preoccupation with RCTs as providing the 'purest' form of research evidence. The seductive allure of the RCT, with its simple answers to complex questions, has proved too great for public health researchers, funders and policy makers to ignore.

It is precisely this 'cleanness' of the male circumcision RCTs in comparison to the 'messiness' of the observational studies that preceded them that made them so attractive to programmers and policy makers. After all, the raison d'etre of the RCT is to isolate the contribution of a single factor to the outcome of interest and results are deliberately decontextualized (Dowsett \& Crouch, 2007). However, Victora, Habicht and Bryce (2004) have pointed to the problems with unquestioningly transposing evidence hierarchies devised in the context of clinical interventions to public health interventions. In their words, "the causal pathways for public health interventions involve not just biological but also behavioral steps that need to be understood and measured, to demonstrate a logical sequence between intervention and outcome" (p. 401, emphasis added).

Yet, despite these limitations, the three RCTs effectively replaced all earlier forms of evidence. This process of effacement is evident in the 2009 Cochrane review, where the observational evidence is relegated to the background section and dismissed in a sentence: "Since the 1980s, observational studies have suggested an association between male circumcision and HIV infection in males" (p. 2). These studies-and the complexity they highlighted around the impact of co-morbid STDs, ethnicity, age, marital status, history of commercial sex encounters, and so on-became useful in explaining the impetus for the RCTs but essentially irrelevant once the 'real' evidence was in.

The Cochrane review's confirmation that: "Male circumcision can be considered as an effective measure to partly prevent HIV acquisition in heterosexual men" (p. 19) provided independent verification that the link had been conclusively proved once and for all. Indeed, the Cochrane reviewers actively dismissed the need for further research, arguing that: "Research on the effectiveness of male circumcision for preventing HIV acquisition in heterosexual men is complete. No further trials are required to establish this fact" (p. 19, emphasis added). Despite the relatively short duration of the trials and their confinement to a single geographic region, their results were presented in absolute terms. Although subsequent follow up studies at 
the trial sites did suggest that the protective effects of male circumcision were sustained long term (Agot et al., 2007; Mattson et al., 2008; Bailey et al., 2008, 2010; Gray et al., 2012), my point is that this information was considered unnecessary-it became merely icing on a policy cake that funders and programmers were already biting into.

More importantly, the results were seen to be relevant not just for men in subSaharan Africa, but men across the globe. Before the RCTs were conducted, Bonner (2001) urged caution in interpreting male circumcision as an answer to the problem of epidemic HIV transmission. She argued that:

Until we know why and how circumcision is protective, exactly what the relationship is between circumcision status and other STIs, and whether the effect seen in high-risk populations is generalisable to other groups, the wisest course is to recommend risk reduction strategies of proven efficacy, such as condom use (p. 152).

None of the questions Bonner raised have been adequately answered today. We still don't understand how and why circumcision is protective (although various theories regarding biological mechanisms for transmission exist) or whether the effects observed in sub-Saharan Africa are generalizable to other groups and settings. However, the Cochrane review made these questions largely irrelevant. This is because the Cochrane review established the association as an incontrovertible fact of nature. As I have previously noted, under the logic of evidence-based medicine and its intellectual offspring, "Interventions retain their efficacy across time and space because culture, meaning and context are irrelevant" (Bell, 2012, p. 318).

The unquestioning transposition of physiological interventions carried out in subSaharan Africa to other countries seems especially problematic given the unique contours of HIV/AIDS transmission in that region in comparison to the rest of the world (e.g., pandemic levels of HIV and high rates of heterosexual transmission). Pointing to important epidemiological differences between the HIV epidemic in subSaharan Africa and the USA, Sullivan et al. (2007) argue that a protective effect from circumcision is unlikely to be found in settings where HIV prevalence is lower. In their words, "The results of any trial must be interpreted with the caution that inference not be extended to populations differing from the study participants in important ways" (p. 1162).

However, on the basis of the RCTs and the Cochrane review, researchers are now raising the possibility of incorporating male circumcision into HIV prevention initiatives in regions such as Papua New Guinea (Hill et al., 2012; Kelly et al., 2012), the Dominican Republic (Brito et al., 2009), the Caribbean (Duncan, 2010) and Thailand (Tieu et al., 2010). Although the rise of evidence-based medicine enabled the 'male circumcision effect' to be taken as given, can we assume that the operation would have the same effect globally? Let me be clear that I am not invoking some kind of distinct racialized response to circumcision on the part of sub-Saharan Africans. Instead, what I want to suggest, qua Lock (2001), is that biological events are contingent-based on biology and the social, environmental and political contexts in which individuals live. As Lock (2001) notes: "The material body cannot stand, as has so often been the case, as an entity that is black-boxed and assumed to be universal, with so much sociocultural flotsam layered over it. The material and 
the social are both contingent-both local" (p. 484). Yet, as we have seen, the notion of contingency has no place in evidence-based medicine.

\section{The politics of HIV/AIDS and the push for biomedical intervention}

Although the rise of evidence-based medicine provides an essential context for understanding the readiness to incorporate male circumcision into HIV prevention, the simple answers it provided were also attractive for reasons connected to the broader politics of HIV/AIDS.

The late 1980s saw the rise of 'behavioral' approaches to HIV/AIDS underwritten by cognitive-behavioral theories of health behavior change (Parker, 2013). The ABC strategy (Abstinence, Be faithful, use a Condom) is the best-known example of this approach. However, such frameworks drew criticism from a variety of disparate quarters. First, the ABC strategy got caught up in the "culture wars" between advocates of condoms and advocates of abstinence (Shelton, 2007, p. 1811; see also Barnett \& Parkhurst, 2005). For example, until 2008 PEPFAR was required to spend at least 33\% of its prevention funding on abstinence and fidelity programs, primarily because of the influence of religious conservative views on its policies (Dietrich, 2007; Patterson, 2010). The agency's interpretation of the ABC strategy garnered particular criticism, primarily because of its weighting towards abstinenceonly messages for young people and view that condoms should only be promoted to those groups practicing "high risk" behaviors (Avert.org, 2013).

For entirely different reasons, numerous social scientists were critical of the behavioral paradigm and advocated for approaches addressing the structural sources of inequality that facilitate and hasten HIV transmission (e.g., Packard \& Epstein, 1991; Farmer, 1999, 2005; Parker, Easton \& Klein, 2000; Parker, 2001; Basu, 2004). Critics highlighted the problems with a decontexualized focus on sexual 'risk' behaviors that assumed that if people just know how HIV is transmitted, HIV transmission rates will diminish (Basu, 2004). In the words of Farmer (1999, p. 86):

Through this cognitivist legerdemain, we have expediently moved the locus of the problem-and thus the focus of the interventions-away from certain features of an inegalitarian society and toward women deemed 'at risk'. The problem is with the women; thus the interventions should change the women.

Various figures responded aggressively to the critiques, charging that such 'political correctness' merely served to obscure the real causes of the epidemic, most notably James Chin, the ex-chief of the Surveillance, Forecasting and Impact Assessment Unit of the Global Programme on AIDS at the World Health Organization. According to Chin's (2007) book The AIDS Pandemic: the Collision of Epidemiology with Political Correctness, Farmer (along with the World Health Organization and UNAIDS), "may have to assume some responsibility for the current abysmal AIDS situation in South Africa since they continue, without any scientific support, to invoke poverty as a major determinant of high HIV prevalence" (p. 150). For Chin, the real problem-one elided through talk of structural issues-is concurrent sexual partnerships. Shelton and Epstein, among others, have made similar arguments, with Epstein (2008, p. 1265) highlighting the "irrationality" of responses promoted by a "needlessly overcomplicated view of the epidemic" and Shelton (2007) charging 
that commonly held views about the influence of poverty and discrimination, gender inequalities, etcetera, on the epidemic are "myths" that need to be dispelled. Both emphasize the importance of tackling head on the 'real' issue: concurrent sexual partnerships.

However, even staunch defenders of the view that the epidemic is primarily due to individual-level (albeit culturally sanctioned) 'risky behaviors' have expressed reservations about the ability of standard behavioral approaches to quell it. For example, Halperin and Epstein (2004) highlight the importance of partner-reduction strategies, but take the view that condom promotion is likely to be ineffective, quoting a review commissioned by UNAIDS which states that "no clear examples have emerged yet of a country that has turned back a generalized epidemic primarily by means of condom promotion" (p. 5). Similarly emphasizing the value of partner-reduction strategies, Shelton (2007, p. 1810) argues: "condoms alone have limited impact in generalised epidemics". Chin (2007, p. 151) laments the fact that behavioral interventions have proved notoriously ineffective to date in transforming "risky behaviors" and in the view of Potts et al. (2008, p. 749), "condom use has not reached a sufficiently high level, even after many years of widespread and often aggressive promotion, to produce a measurable slowing of new infections in the generalized epidemics of Sub-Saharan Africa". ${ }^{3}$ Although Potts et al. highlight the potential value of multiple partner reduction strategies, they note that there are "few demonstrated replicable approaches to reducing multiple sexual partnerships on a large scale" (p. 750).

In my view, these disparate factors, in combination with the reality of an epidemic that continues unabated in many parts of sub-Saharan Africa, facilitated a policy environment in which there was a degree of receptivity to a 'new' biomedical approach to HIV prevention, one based on a "more thoroughgoing engagement with the principles of 'traditional' public health medicine" (Aggleton, 2007, p. 20). As Parker (2013) observes, faced with the difficulties of transforming structural factors and the limited success of behavioral approaches, there has been a rush to return to biomedical solutions driven by a variety of forces, from industry, research funders, biomedical and behavioral researchers themselves and the public health establishment. ${ }^{4}$

From a programming perspective, circumcision resolves the debate about the respective merits of behavioral versus structural approaches to HIV prevention by sidestepping it completely. As previously stated, the whole point of the RCTs was to isolate the impact of male circumcision on HIV transmission, regardless of individual sexual behavior and regardless of the socio-economic context of the procedure. Thus, although advocates are careful to stress that male circumcision should be offered as part of a larger HIV prevention package, they simultaneously note that: "unlike other HIV prevention strategies, MC is a one-time procedure conferring potentially lifelong protective benefits" (e.g., Potts et al., 2008, p. 750; Wamai et al., 2011, p. 3, emphasis added). As a protective factor "independent" of the "number of sex partners and frequency of partner exchange" (Chin, 2007, p.146) male circumcision has the advantage of being an intervention that does not rely on individual behavior (or structural change) to be effective. According to Klausner et al. (2008, p. 3), "circumcision appears akin to a 'strong immunization', whose 
benefits would probably be extremely difficult to offset through such behavioral disinhibition". In such framings the 'magic bullet' metaphor is simultaneously disclaimed and invoked. Thus, Wamai et al. (2011, p. 12) argue that: "We support the continued promotion of the use of all effective methods. The effect of doing so will be cumulative" (the disclaimer) but go onto conclude that male circumcision is a “surgical vaccine' for the $21^{\text {st }}$ century" (the magic bullet).

From a funding perspective, male circumcision is also attractive for a variety of reasons. First, although some commentators worry that the ' $\mathrm{C}$ ' of the ABC approach to HIV prevention may come to stand for 'circumcision' rather than 'condom use' (e.g., Lazarus, Giordano \& Matic, 2008), for organizations influenced by religious conservative agendas, this is potentially a boon rather than a problem, because circumcision is more politically palatable than promoting condom use. Indeed, it is worth noting that PEPFAR - the same organization that historically shied away from the ' $\mathrm{C}$ ' of the $\mathrm{ABC}$ strategy-is today a key funder of male circumcision initiatives. Second, research and policy agendas have been influenced by a willingness to embrace solutions that attract funds from organizations such as the Gates Foundation (Aggleton, 2007). As Birn (2005, p.2) notes, in calling on the world's researchers to develop 'innovative' global health solutions, the Gates Foundation has "turned to a narrowly conceived understanding of health as the product of technical interventions divorced from economic, social, and political contexts".

\section{Male circumcision and 'African sexuality'}

So far I have focused largely on international developments that supported the implementation of male circumcision in HIV prevention - the rise of EBM and the broader politics of HIV/AIDS research and funding. In many respects, these developments were not specific to the epidemic in Africa, although they primarily affected this region. However, some accounts of the value of male circumcision do seem to be informed by a particular view of the nature of African culture and sexuality.

Numerous scholars have argued that understandings of the HIV/AIDS epidemic in Africa have been underpinned by the assumption of a singular 'African sexuality' characterized by promiscuity, gender violence and a lack of internalized moral restraints (Packard \& Epstein, 1991; Bibeau \& Pederson, 2002; Stillwaggon, 2003; Basu, 2004). There is something of this feel to Chin's (2007) discussion of the drivers of AIDS in sub-Saharan Africa. Chin argues that while up to $20 \%$ of adults in some Western countries have mostly serial sexual relationships with between 1 and 10 partners on a monthly or yearly basis, $20-40 \%$ of people in some subSaharan African countries have between 1 and 100 concurrent sexual partners on a weekly or monthly basis. ${ }^{5}$ What Chin is talking about, as he spells out largely in footnotes, is promiscuity. For Chin, concurrency, the presence of co-morbid sexually transmitted diseases and a widespread cultural preference for 'dry sex', along with a lack of condom use and a lack of male circumcision, have been the primary drivers of the epidemic in sub-Saharan Africa (pp. 65-70). Wamai et al. (2011, p. 2) also emphasize that "promiscuous practices" were one of the key initial drivers of the epidemic in sub-Saharan Africa. Like Chin, they juxtapose concurrency and lack of male circumcision as the key to understanding the rise of the epidemic in Africa. 
For example, in an earlier article they note: "Where multiple sexual partnerships, especially concurrent ones, are uncommon, and particularly where male circumcision is common, HIV infection has remained concentrated in high-risk populations" (Potts et al., 2008, p. 749).

This dual emphasis on cultural patterns of sexual behavior and lack of male circumcision is echoed in the 2008 report of the Commission on HIV/AIDS and Governance in Africa (United Nations Economic Commission for Africa, 2008). In discussing the "core drivers of Africa's HIV and AIDS epidemic", the report highlights "unsafe sex, male circumcision, the presence of other sexually transmitted infections, and young age at first sexual intercourse for girls, as well as concurrent partnering" (pp. 15-16). That 'culture' is the primary culprit is highlighted in a press release outlining the report's key findings; "Some African cultural traditions influence the spread of AIDS", the brief proclaims (UN News Centre, 2008). As Berer (2007, p. 46) observes of the WHO/UNAIDS consultation at Montreux in March 2007 on male circumcision policy, "There was an unstated assumption in the WHO/UNAIDS consultation that unprotected, unsafe sex on the part of men in subSaharan Africa cannot be changed".

Presented in this light, male circumcision becomes a partial 'technical' solution that helps to counterbalance entrenched 'cultural' patterns of sexual behavior. Certainly, this is the message that many sub-Saharan African men have received, and a growing body of acceptability studies demonstrate the ways in which the circumcision/promiscuity link has been forged in local perceptions of the procedure. Thus, while researchers have long been preoccupied with the question of whether male circumcision might lead to sexual 'disinhibition', locals in a variety of countries see circumcision as evidence of promiscuity—or the intent for such (e.g., Makerere University, 2007; Herman-Roloff et al., 2011; Lundsby, Draebel \& Myerowtisch, 2012; Downs et al., 2013). For example, in one recent study, newly-circumcised Zambian men worried that advising other men to be circumcised "could be taken as an insult and as an insinuation that the person is 'a womaniser' or is 'promiscuous"' (Lundsby, Draebel \& Myerowitsch, 2012, p. 356). An earlier acceptability study from Uganda (Makerere University, 2007) highlights similar concerns, with local leaders stating that: "some women might think that male circumcision is for those men who intend to engage in infidelity, change female partners and yet fear to get infected"6 (p. 9) and participants in a Kenyan study report that "if a man wants to get circumcised, his female sex partner(s), neighbors, and/or friends might think that he is promiscuous" (Herman-Roloff et al., 2011).

Although these studies report a general degree of openness towards the implementation of male circumcision as a means of reducing HIV transmission, they show evidence of a complex and ambivalent engagement with the procedure and the stark impossibility of reducing it to a 'technical' act divorced of cultural and historical meaning. Indeed, for at least some observers, these interventions appear to be driven primarily by western agendas and interests. According to Ncayiyana (2011): "It is curious and even worrisome that the campaign to circumcise African men seems to be driven by donor funding and researchers from the North". As Skinner (2010, p. 158) wonders: "is the mostly 'Western' scientific data immune to the aestheticization of hygiene, or the role that racism often plays in conceptualizing 
African bodies as sites of neocolonial intervention?" I'm certainly not arguing that all supporters of male circumcision or advocates of concurrency theories are racist. But I do want to suggest that the emergence of male circumcision as a HIV prevention tool in sub-Saharan Africa cannot be entirely divorced from longstanding medical and colonial discourses about the 'sexual life of the natives' (Packard \& Epstein, 1991, p. 781).

Based on ethnographic fieldwork on HIV/AIDS prevention clinical trials in East Africa, Elliott (in press) has highlighted their resonances with the lengthy history of experimentation by colonial and imperial powers on the bodies of the subaltern. She argues that these contemporary entanglements between science and politics look eerily similar to "colonial configurations of oppression and resource (and knowledge) extraction". Particularly telling is her report of an encounter in 2007 in Kisumu, Kenya with a young Luo man about the efficacy of male circumcision in reducing HIV transmission. She describes the encounter as follows:

When I told him that I was there doing ethnographic research on HIV trials, he wanted to know if I knew anything about the UNIM trial. UNIM, a collaboration between the universities of Nairobi, Illinois and Manitoba, was one of three trial sites exploring male circumcision as an HIV prevention strategy. The driver asked me - does it work? We discussed the findings, and then he wanted to know - What do they do with the foreskins? Is it true that they ship them to America? I didn't know. I wanted to say 'no, of course not' but it was possible. And in fact a few weeks later I met the PI of that trial for the first time, and I told him my story, and he confirmed that yes indeed they did ship tissue foreskin samples to Winnipeg and Chicago for analysis.

As Elliott observes, these concerns about what happens to the foreskins removed from Kenyan men connect with longstanding local rumors and stories about western powers and blood stealing. White (1993) has extensively documented the history of these stories in east and central Africa. Some feature accounts of illicit medical experiments performed by colonial administrations; others include employees driving around in vehicles and stealing blood from local men. According to one 1947 report from the former superintendent of police in Dar es Salaam, the practice of fire engines carrying blood donors to the hospital soon gave rise to the rumor "that the vehicles, usually with a European volunteer in charge, were collecting African males for their blood and that it was a plot by Europeans to render them impotent" (White, 1993, p. 32).

If we have learnt anything from the history of colonial and post-colonial efforts to eradicate female genital surgery, it's that interventions enacted in the name of health cannot always be disentangled from underlying assumptions about the nature of African Others; moreover, locals are generally well aware that more is at stake than 'health'-especially when those interventions relate to a procedure so intimately tied with gender, sexuality and identity (James, 1998; Shweder, 2000; Boddy, 2007; Shell-Duncan \& Hernlund, 2000; Hernlund \& Shell-Duncan, 2007; PPANFGSA, 2012). Why should we assume that this would be any less true of male circumcision? After all, despite its rendering as a straightforward 'biomedical technology of prevention', this is no value-neutral procedure but a profoundly 
significant and meaningful symbolic act (Silverman, 2004, 2006).

\section{Conclusion}

To date, discussions of the utility of male circumcision as a HIV prevention tool have centered primarily on its status as a matter of fact; however, as the current debates show, male circumcision is so "beautifully complex and entangled" it resists being treated as such (c.f. Latour, 2004, p. 234). Is there evidence 'out there' that the procedure serves to reduce HIV transmission in sub-Saharan Africa? Yes. But that alone tells us little about why it became seen as a viable strategy for dealing with the problem of HIV/AIDS more broadly; evidence alone does not inevitably inspire an appetite for intervention.

Although dominant public health discourses on the relationship between male circumcision and HIV prevention suggest this is a straightforward instance of evidence and uptake, the rise of male circumcision as a HIV prevention tool cannot be explained merely by the emergence of irrefutable evidence and the subsequent uptake of this knowledge by public health funders and policy makers. Nor can it be understood as the result of the coordinated efforts of a group of pro-circumcision advocates to influence global HIV/AIDS agendas. In my view, the current polarized landscape leaves little space for open and considered discussions of this topic.

The embrace of male circumcision as a weapon in the arsenal of HIV prevention cannot be disentangled from the rise of evidence-based medicine, or the politics of HIV/AIDS research and funding. The tools of evidence-based medicine (RCTs and meta-analyses) ostensibly served to 'isolate' the effectiveness of the procedure from its behavioral, social and cultural setting and such simplicity was attractive to programmers and policy makers, given the fraught politics of HIV/AIDS prevention. However, although the possibility of a body unencumbered by society and culture is a basic premise of biomedicine, as anthropologists have long observed, this assumption fails to hold up in practice (e.g., Scheper-Hughes \& Lock, 1987; Lock, 2001; Moerman, 2002). I appreciate the need to find answers to an epidemic that has cost countless lives, but while reducing complexity might seem like the solution, the answers it provides are likely to be partial and misleading.

\section{Acknowledgements}

First and foremost, I'd like to acknowledge the research assistance of Maggie Woo. Maggie's consummate skill in conducting literature searches, preparing literature summaries, hunting down obscure references and generally acting as an enthusiastic sounding board has been invaluable and I acknowledge my debt to her here (needless to say, she is not responsible for the arguments presented herein and any ire should be directed to me alone). It will probably come as little surprise that this paper has been reviewed many times by many people, relatively evenly divided between those who supported its central arguments and those who categorically rejected them. Their comments have fundamentally shaped the final paper and while I can't thank them in person (given that all reviews were anonymous), I acknowledge their contributions here. I'm also grateful to Darlene McNaughton and Vinay Kamat, both of whom provided constructive critical feedback on earlier versions of the manuscript, and Richard Parker, whose email invitation to submit a manuscript on this topic came at just the right moment. 


\section{Notes}

${ }^{1}$ Fink's primary purpose in writing the letter seems to have been to push for the continued healthcare coverage of neonatal circumcision as opposed to any particular interest in HIV/AIDS.

${ }^{2}$ One such example is CircLeaks (www.circleaks.org), a website styled along the lines of WikiLeaks which describes itself as "A place to learn about those who fund, promote, and profit from circumcision". A conspiratorialist tone pervades the website and profiles focus on elucidating the ways in individuals, institutions and organizations are secretly (or not-so-secretly) "circumcision promoters". For example, Stephen Lewis, a former head of UNAIDS, is denounced as Jewish and an "outspoken feminist".

${ }^{3}$ Although proponents of male circumcision tend to downplay the effectiveness of condom promotion, it is often cited as an important component of successful HIV prevention initiatives in countries such as Uganda (e.g., Parkhurst \& Lush, 2004; Kirby, 2008).

4 This embrace of biomedical responses also speaks to broader processes of 'biomedicalization' (Clarke et al., 2010), with interventions progressively more reliant on science and technology and focusing on transforming bodies for the purposes of both treatment and enhancement.

${ }^{5}$ Although Chin berates others for their carelessness with numbers, he provides no citations for these figures, although at their higher levels they stretch the bounds of credulity.

${ }^{6}$ I have not discussed the role of gender in the acceptance of male circumcision as a HIV prevention tool, although this is a topic worthy of analysis in its own right (see Berer, 2007).

\section{References Cited}

Agot, K.E., Kiarie, J.N., Nguyen, H.Q., Odhiambo, J.O., Onyango, T. \& Weiss, N. (2007). Male circumcision in Siaya and Bondo districts, Kenya: Prospective cohort study to assess behavioral disinhibition following circumcision. Journal of Acquired Immune Deficiency Syndrome, 44(1), 66-70.

Aggleton, P. (2007). 'Just a snip'? A social history of male circumcision. Reproductive Health Matters, 15(29), 15-21.

Bell, K. (2005). Genital cutting and western discourses on sexuality. Medical Anthropology Quarterly, 19(2), 125-148.

Bell, K. (2012). Cochrane reviews and the behavioural turn in evidence-based medicine. Health Sociology Review, 21(3), 313-321.

Auvert, B., Taljaard, D., Lagarde, E., Sobngwi-Tambekou, J., et al. (2005). Randomized controlled intervention trial of male circumsision for reduction of HIV infection risk: the ANRS 1265 Trial. PLoS Medicine, 2(11), e298.

Avac, National Empowerment Network of People Living with HIV/AIDS in Kenya, Sonke Gender Justice Network and Uganda Network of AIDS Service Organizations. (2012). A call to action on voluntary medical male circumcision: Implementing a key component of combination HIV prevention. Retrieved from 
http://www.avac.org/ht/a/GetDocumentAction/i/44846 (accessed, June 18, 2013).

Avert.org (2013). HIV prevention strategies. Retrieved from http://www.avert.org/abc-hiv.htm (accessed June 18, 2013).

Bailey, R.C., Moses, S., Parker, C.B., Agot, K., et al. (2007). Male circumcision for HIV prevention in young men in Kisumu, Kenya: a randomized controlled trial. Lancet, 369, 643-656.

Bailey, R.C., Moses, S., Parker, C.B., Agot, K., et al. (2008) The protective effect of male circumcision is sustained for at least 42 months: Results from the Kisumu, Kenya trial. XVII International AIDS Conference, Mexico City.

Bailey, R.C., Moses, S., Parker, C.B., Agot, K., et al. (2010). The protective effect of adult male circumcision against HIV acquisition is sustained for at least 54 months: Results from the Kisumu, Kenya trial. XVIII International AIDS Confererence, Vienna.

Banerjee, J., Klausner, J.D., Halperin, D.T., Wamai, R., et al. (2011). Circumcision denialism unfounded and unscientific. American Journal of Preventive Medicine, 40(3), e11-e12.

Barnett, T. \& Parkhurst, J. (2005). HIV/AIDS: sex, abstinence, and behaviour change. Lancet Infectious Diseases, 5(5), 590-593.

Barongo, L.R., Borgdorff, M.W., Mosha, F.F., Nicoll, A., et al. (1992). The epidemiology of HIV-1 infection in urban areas, roadside settlements and rural villages in Mwanza Region, Tanzania. AIDS, 6(12), 1521-1528.

Basu, S. (2004). AIDS, empire and public health behaviorism. International Journal of Health Services, 34(1), 155-167.

Berer, M. (2007). Male circumcision for HIV prevention: Perspectives on gender and sexuality. Reproductive Health Matters, 5(29), 45-48.

Bibeau, G. \& Pederson, D. (2002). A return to scientific racism in medical social sciences: the case of sexuality and the AIDS epidemic in Africa. In M. Nichter \& M. Lock (Eds.) New horizons in medical anthropology: Essays in honour of Charles Leslie (pp. 141-171). London: Routledge.

Birn, A-E. (2005). Gate's grandest challenge: Transcending technology as public health ideology. Lancet, 366(9484), 514-519.

Boddy, J. (2007). Civilizing women: British crusades in colonial Sudan. Princeton, NJ: Princeton University Press.

Bongaarts, J., Reining, P., Way, P. \& Conant, F. (1989). The relationship between male circumcision and HIV infection in African populations. AIDS, 3, 373-377.

Bonner, K. (2001). Male circumcision as an HIV control strategy: not a 'natural condom'. Reproductive Health Matters, 9(18), 143-155.

Boyle, G.J. \& Hill, G. (2011). Sub-Saharan African randomised clinical trials into male circumcision and HIV transmission: methodological, ethical and legal concerns. Journal of Law and Medicine, 19, 316-334.

Brito, M.O., Caso, L.M., Balbuena, H. \& Bailey, R.C. (2009). Acceptability of male circumcision for the prevention of HIV/AIDS in the Dominican Republic. PLoS One, 4(11), e7687.

Bwayo, J., Plummer, R., Omari, M., Mutere, A., Moses, S., et al. (1994). Human immunodeficiency virus infection in long-distance truck drivers in east Africa. Archives of Internal Medicine, 154, 1391-1396 
Caldwell, J. \& Caldwell, P.C. (1994). The neglect of an epidemiological explanation for the distribution of HIV/AIDS in sub-Saharan Africa: Exploring the male circumcision hypothesis. Health Transition Review, 4(Suppl), 23-46.

de Camargo Jr., K.R., de Oliveira Mendonça, A.L., Perrey, C. \& Giami, A. (2013). Male circumcision and HIV: a controversy study on facts and values. Global Public Health, 8(7), 769-783.

Cameron, D.W., D’Costa, L.J., Maitha, G.M., Cheang, M., et al. (1989). Female to male transmission of human immunodeficiency virus type 1: Risk factors for seroconversion in Men. Lancet, 2, 403-407.

Carpenter, L.M. (2010). On remedicalisation: Male circumcision in the United States and Great Britain. Sociology of Health and Illness, 32(4), 613-630.

Casper, M.J. \& Clarke, A.E. (1998) Making the pap smear into the 'right tool' for the job: Cervical cancer screening in the USA, circa 1940-95. Social Studies of Science, 28(2): 255-90.

Chin, J. (2007). The AIDS pandemic: the collision of epidemiology with political correctness. Abingdon, UK: Radcliffe Publishing.

Clarke, A.E., Mamo, L., Fosket, J.R., Fishman, J.R. \& Shim, J.K. eds. (2010). Biomedicalization: Technoscience, health and illness in the U.S. Durham: Duke University Press.

Cohen, A.M., Stavri, P.Z. \& Hersh, W.R. (2004). A categorization and analysis of the criticisms of evidence-based medicine. International Journal of Medical Informatics, 73, 35-43.

Dietrich, J.W. (2007). The politics of PEPFAR: the President's emergency plan for AIDS relief. Ethics \& International Affairs, 21(3), 277-292.

Downs, J.A., Fuunay, L.D., Fuunay, M., Mbago, M., et al. (2013). 'The body we leave behind': a qualitative study of obstacles and opportunities for increasing uptake of male circumcision among Tanzanian Christians. BMJ Open, 3, $\mathrm{e} 002802$.

Dowsett, G.W. \& Crouch, M. (2007). Male circumcision and HIV prevention: is there really enough of the right kind of evidence? Reproductive Health Matters, 15(29), 33-44.

Duncan, N.D. (2010). Male circumcision and the Caribbean HIV epidemic. West Indian Medical Journal, 59(4).

Elliott, D. (in press). Imagining 'Atlanta': the politics and poetics of space and marginality in medical research in East Africa. Cultural Studies Review.

Epstein, H. (2008) AIDS and the irrational. British Medical Journal, 337, 12651267.

Farmer, P. (1999). Infections and inequalities: the modern plagues. Berkeley: University of California Press.

Farmer, P. (2005). Pathologies of power: Health, human rights and the new war on the poor. Berkeley: University of California Press.

Fink, A.J. (1986). A possible explanation for heterosexual male infection with AIDS. New England Journal of Medicine, 315(18), 1167.

Fink, A.J. (1988). Circumcision: a parent's decision for life. Kavanah Publishing.

Fleck, L. (1979). Genesis and development of a scientific fact. T.J. Trenn \& R.K. Merton (Eds). Chicago: University of Chicago Press.

Fox, M. \& Thomson, M. (2010). HIV/AIDS and circumcision: lost in translation. Journal of Medical Ethics, 36, 798-801. 
Gard, M. (2011). Truth, belief and the cultural politics of obesity scholarship and public health policy. Critical Public Health, 21(1), 37-48.

Gilks, C.F., Otieno, L.S., Brindle, R.J., Newnham, R.S., et al. (1992). The presentation and outcome of HIV-related disease in Nairobi. Quarterly Journal of Medicine, 82(279), 25-32.

Goldenberg, M.J. (2006). On evidence and evidence-based medicine: Lessons from the philosophy of science. Social Science and Medicine, 62, 2621-2632.

Gray, R.H., Kigozi, G., Serwadda, D., Makumbi, F., et al. (2007). Male circumcision for HIV prevention in men in Rakai Uganda: a randomized trial. Lancet, 369, 657-666.

Gray, R., Kigozi, G., Kong, X., Ssempiija, V., Makumbi, F., Wattya, S., Serwadda, D., Nalugoda, F., Sewenkambo, N.K. \& Wawer, M.J. (2012). The effectiveness of male circumcision for HIV prevention and effects on risk behaviors in a posttrial follow-up study. AIDS, 26(5), 609-615.

Green, L.W., McAllister, R.G., Peterson, K.W., Travis, J.W. (2008). Male circumcision is not the HIV vaccine we've been waiting for! Future HIV Therapy, 2(3), 193-199.

Green, L.W., Travis, J.W., McAllister, R.G., Peterson, K.W., et al. (2010). Male circumcision and HIV prevention: Insufficient evidence and neglected external validity. American Journal of Preventive Medicine, 39, 479-482.

Greenblatt, R.M., Lukehart, S.A., Plummer, F.A., Quinn, T.C., et al. (1988). Genital ulceration as a risk factor for human immunodeficiency virus infection. AIDS, 2(1), 47-50.

Halperin, D.T. \& Bailey, R.C. (1999). Male circumcision and HIV infection: 10 years and counting. Lancet, 354, 1813-15.

Halperin, D.T. \& Epstein, H. (2004) Concurrent sexual partnerships help to explain Africa's high HIV prevalence: implications for prevention. Lancet, 364, 4-6.

Herman-Roloff, A., Otieno, N., Agot, K., Ndinya-Achola, J. \& Bailey, R.C. (2011). Acceptability of medical male circumcision among uncircumcised men in Kenya one year after the launch of the national male circumcision program. PLoS One, 6(5): e19814.

Hernlund, Y. \& Shell-Duncan, B. (2007). Transcultural bodies: Female genital cutting in global context. New Brunsick, NJ: Rutgers University Press.

Hill, P.S., Tynan, A., Law, G, Millan, J., et al. (2012). A typology of penile cutting in Papua New Guinea: Results of a modified Dephi study among sexual health specialists. AIDS Care, 24(1), 77-86.

Hira, S.K., Kamanga, J., Macuacua, R., Mwanza, N., et al. (1990). Genital ulcers and male circumcision as risk factors for acquiring HIV-1 in Zambia. Journal of Infectious Diseases, 161, 584-585.

James, S. (1998). Shades of othering: reflections on female circumcision/genital mutilation. Signs, 23(4),1031-1048.

Kelly, R., Kiwanuka, N., Wawer, M.J., Serwadda, D., et al. (1999). Age of male circumcision and risk of prevalent HIV infection in rural Uganda. AIDS, 13(3), 399-405.

Kelly, A., Kupul, M., Fitzgerald, L., Aeno, H., Neo, J., Naketrumb, R., Siba, P., Kaldor, J.M. \& Vallely, A. (2012). 'Now we are in a different time; various bad diseases have come'. Understanding men's acceptability of male circumcision 
for HIV prevention in a moderate prevalence setting. BMC Public Health, 12:67.

Kirby, D. (2008). Changes in sexual behaviour leading to the decline in the prevalence of HIV in Uganda: Confirmation from multiple sources of evidence. Sexually Transmitted Infections, 84, ii35-ii41.

Klausner, J.D., Wamai, R.G., Bowa, K., Agot, K., Kagimba, J. \& Halperin, D.T. (2008). Is male circumcision as good as the HIV vaccine we've been waiting for? Future HIV Therapy, 2(1), 1-7.

Klawiter, M. (2008). The biopolitics of breast cancer: Changing cultures of disease and activism. Minneapolis, MN: University of Minnesota Press.

Lambert, H. (2006). Accounting for EBM: Notions of evidence in medicine. Social Science and Medicine, 62, 2633-2645.

Lancet (2007). Newer approaches to HIV prevention. Lancet, 369: 15.

Latour, B. (2004). Why has critique run out of steam? From matters of fact to matters of concern. Critical Inquiry, 30(2), 225-248.

Latour, B. (2008). What is the Style of Matters of Concern? Assen, The Netherlands: Van Gorcum.

Lazarus, J.V., Giordano, N., \& Matic, S. (2008). Male circumcision in HIV prevention: Some implementation caveats. HIV Medicine, 9(6), 327-328.

Lock, M. (2001). The tempering of medical anthropology: Troubling natural categories. Medical Anthropology Quarterly, 15(4), 478-492.

Lundsby, K., Draebel, T. \& Meyrowitsch, D.W. (2012). 'It brought joy in my home as in the area of my wife'. How recently circumcised adult men ascribe value to and make sense of male circumcision. Global Public Health, 7(4), 352-366.

Makerere University. (2007). Situation analysis to determine the acceptability and feasibility of male circumcision promotion in Uganda. Kampala: Family Health International.

Mattson, C.L., Campbell, R.T., Bailey, R.C., Agot, K., Ndinya-Achola, J.O. \& Moses, S. (2008) Risk compensation is not associated with male circumcision in Kisimu, Kenya: a multi-faceted assessment of men enrolled in a randomized controlled trial. PloS One, 3(6): 23443.

Mbugua, G.G., Muthami, L.N., Mutura, C.W., Oogo, S.A., et al. (1995). Epidemiology of HIV infection among long distance truck drivers in Kenya. East African Medical Journal, 72(8), 515-518.

McGuire, W. (2005). 'Beyond EBM: New directions for evidence-based public health'. Perspectives in Biology and Medicine, 48(4), 557-569.

Mills, E., Cooper, C., Anema, A. \& Guyat, G. (2008). Male circumcision for the prevention of heterosexually acquired HIV infection: a meta-analysis of randomized trials involving 11050 men. HIV Medicine, 9(6), 332-335.

Moerman, D. (2002). Meaning, medicine and the "placebo effect". Cambridge, MA: Cambridge University Press.

Moses, S., Bradley, J.E., Nagelkerke, N.J.D., Ronald, A. et al. (1990). Geographical patterns of male circumcision practices in Africa: Association with HIV seroprevalence. International Journal of Epidemiology, 19(3), 693-97.

Mykhalovskiy, E. \& Weir, L. (2004). The problem of evidence-based medicine: Directions for social science. Social Science and Medicine, 59, 1059-1069. 
Ncayiyana, D.J. (2011). The illusive promise of circumcision to prevent female-tomale HIV infection - not the way to go for South Africa. South African Medical Journal 101(11). http://samj.org.za/index.php/samj/article/view/5384/3655

Newell, M-L. \& Bärnighausen, T. (2007) Male circumcision to cut HIV risk in the general population. Lancet, 369: 617-619.

Oudshoorn, N. (2003). The male pill: a biography of a technology in the making. Durham, NC: Duke University Press.

Packard, R. M. \& Epstein, P. (1991). Epidemiologists, social scientists, and the structure of medical research on AIDS in Africa. Social Science and Medicine, 33(7), 771-794.

Parker, R. (2001). Sexuality, culture and power in HIV/AIDS research. Annual Review of Anthropology, 30, 163-179.

Parker, R. (2013). Shifting paradigms in HIV prevention and research. Paper presented at Centers for AIDS Research Social and Behavioral Sciences Research Network $7^{\text {th }}$ National Scientific Meeting Social, Behavioral, and Policy Perspectives on HIV/AIDS: the District of Columbia and Beyond. Washington DC, October 22-24.

Parker, R.G., Easton, D. \& Klein, C.H. (2000). Structural barriers and facilitators in HIV prevention: a review of international research. AIDS, 14(suppl 1), S22S32.

Parkhurst, J.O. \& Lush, L. (2004). The political environment of HIV: Lessons from a comparison of Uganda and South Africa. Social Science \& Medicine, 59(5), 1913-1924.

Patterson, J. (2010). Faith-based organizations and AIDS: the good, the bad, and the ugly. Achieve: a Quarterly Journal on HIV Prevention, Treatment and Politics, Winter, 1-4.

PEPFAR. (n.d.). Male circumcision. Retrieved from http://20062009.pepfar.gov/documents/organization/107820.pdf (accessed March 17, 2012).

PEPFAR. (2013). Latest results. Retrieved from http://www.pepfar.gov/funding/results/ (accessed December 16, 2013).

Pison, G., Guenno, B.E., Lagarde, E., Enel, C., \& Seck, C. (1993). Seasonal

migration: a risk factor for HIV infection in rural Senegal. Journal of Acquired

Immune Deficiency Syndromes, 6, 196-200.

Potts, M., Halperin, D.T., Kirby, D., Swidler, A., et al. (2008). Reassessing HIV prevention. Science, 320, 749-750.

Public Policy Advisory Network on Female Genital Surgeries in Africa (PPANFGSA) (2012). Seven things to know about female genital surgeries in Africa. Hastings Center Report, November-December,19-27.

Quigley, M., Munguti, K., Grosskurth, H., Todd, J., et al. (1997). Sexual behaviour patterns and other risk factors for HIV infection in rural Tanzania: a casecontrol study. AIDS, 11(2), 237-248.

Rennie, S. (2007). Ethics of using male circumcision for HIV prevention: Exploring the middle ground. Therapy, 4(6), 731-735.

Rose, Dy. (2010). Male circumcision a 'surgical vaccine'. Sydney Morning Herald. Retrieved from http://news.smh.com.au/breaking-news-national/malecircumcision-a-surgical-vaccine-20100919-15hm3.html (accessed December 13, 2011). 
Scheper-Hughes, N. \& Lock, M. (1987). The mindful body: a prolegomenon to future work in medical anthropology. Medical Anthropology Quarterly, 1(1), 6-41.

Shell Duncan, B. \& Hernlund, Y. (2000). Female 'circumcision' in Africa: Culture, controversy, and change. Boulder, CO: Lynne Rienner Publishers.

Shelton, J.D. (2007). Ten myths and one truth about generalised HIV epidemics. Lancet, 370, 1809-1811.

Shweder, R.A. (2000). What about 'female genital mutilation'? And why understanding culture matters in the first place. Daedalus, 129(4), 209-232.

Siegfried, N., Muller, M., Deeks, J., Volmink, J., et al. (2005). HIV and male circumcision: a systematic review with assessment of the quality of studies. Lancet Infectious Diseases, 5(3), 165-173.

Siegfried, N., Muller, M., Deeks, J.J. \& Volmink, J. (2009). Male circumcision for prevention of heterosexual acquisition of HIV in men. Cochrane Database of Systematic Reviews, 15(2), CD003362.

Silverman, E.K. (2004). Anthropology and circumcision. Annual Review of Anthropology, 33, 419-445.

Silverman, E.K. (2006). From Abraham to America: a history of Jewish circumcision. Lanham, MD: Rowman \& Littlefield Publishers.

Skinner, D. (2010). The poetics of American circumcision on the margins of medical necessity. In Understanding Emerging Epidemics: Social and Political Approaches. Ananya Mukherjea, ed. Pp. 145-163. Advances in Medical Sociology Volume 11. Emerald Group Publishing Limited.

Stillwaggon, E. (2003). Racial metaphors: Interpreting sex and AIDS in Africa. Development \& Change, 34(5): 809-832.

Sullivan, P.S., Kilmarx, P.H., Peterman, T.A., Taylor, A.W. et al. (2007). Male circumcision for HIV transmission: What new data mean for HIV prevention in the United States. PLoS Medicine, 4(7), 1162-1166.

Tieu, H, Phanuphak, N., Ananworanich, J., Pharachetsakul, N., et al. (2008). Acceptability of male circumcision for prevention of HIV among high-risk heterosexual men in Thailand. Paper presented at AIDS 2008: XVII International AIDS Conference, Mexico City, 3-8 August.

UN News Centre. (2008). Some African cultural traditions influence spread of AIDS - UN report. Retrieved from http://www.un.org/apps/news/story.asp/story.asp?NewsID=26945\&Cr=aids\&Cr 1=\#.Uq5Aeo1AWHk (accessed December 15, 2013).

UNAIDS. (2007a). Male circumcision: Africa's unprecedented opportunity. Geneva, Switzerland: World Health Organization.

UNAIDS. (2007b). New data on male circumcision and HIV prevention: Policy and programme implications. Geneva, Switzerland: World Health Organization.

UNAIDS. (2008). Safe, voluntary, informed male circumcision and comprehensive HIV prevention: Programming guidance for decision-makers on human rights, ethical and legal considerations. Geneva, Switzerland: World Health Organization.

United Nations Economic Commission for Africa. (2008). Securing our future: Report of the Commission on HIV/AIDS and Governance in Africa. Geneva: United Nations.

Urassa, M., Todd, J., Boerma, J.T., Hayes, R., \& Isingo, R. (1997). Male circumcision and susceptibility to HIV infection among men in Tanzania. AIDS, 11(1), 7380. 
USAID. (2011). Male circumcision. Retrieved from http://www.usaid.gov/our_work/global_health/aids/TechAreas/prevention/malec ircumcision.html (accessed October 28, 2011).

Van Howe, R.S., \& Storms, M.R. (2011). How the circumcision solution in Africa will increase HIV infections. Journal of Public Health in Africa, 2(4), 11-15.

Van Howe, R.S., Svoboda, J.S., \& Hodges, F.M. (2005). HIV infection and circumcision: Cutting through the hyperbole. Journal of the Royal Society for the Promotion of Health, 125(6), 259-265.

Victora, C.G., Habicht, J.P., \& Bryce, J. (2004). Evidence-based public health: Moving beyond randomized trials. American Journal of Public Health, 94(3), 400-405.

de Vincenzi, I., \& Mertens, T. (1994). Male circumcision: a role in HIV prevention? AIDS, 8, 153-160.

Wamai, R.G., Morris, B.M., Bailis, S.A., Sokal, D., et al. (2011). Male circumcision for HIV prevention: Current evidence and implementation in sub-Saharan Africa. Journal of the International AIDS Society, 14, 49.

Wamai, R.G., Morris, B.J., Waskett, J.H., Green, E.C., et al. (2012). Criticisms of African trials fail to withstand scrutiny: Male circumcision does prevent HIV infection. Journal of Law \& Medicine, 20, 93-123.

Weiss, H.A., Quigley, M.A. \& Hayes, R.J. (2000). Male circumcision and risk of HIV infection in sub-Saharan Africa: a systematic review and meta-analysis. AIDS, 14(15), 2361-2370.

Westercamp, N. \& Bailey, R.C. (2007). Acceptability of male circumcision for prevention of HIV/AIDS in sub-Saharan Africa: a review. AIDS \& Behavior, 11, 341-355.

White, L. (1993). Cars out of place: vampires, technology, and labor in east and central Africa. Representations, 43(Summer), 27-50. 